\title{
Recolhimento de embalagens vazias de agrotóxicos no Rio Grande do Norte de 2006
} a 2014

\section{Collecting empty containers of pesticides in Rio Grande do Norte 2006-2014}

\author{
$\hat{A}_{n g e l a}$ Saionara Pereira Sousa ${ }^{1 *}$, Rui Sales Júnior $^{2}$, Andreia Mitsa Paiva Negreiros ${ }^{3}$, Teliane Sousa Oliveira ${ }^{1}$
}

Resumo: Os agrotóxicos são substâncias utilizadas para o controle de agentes biológicos não desejáveis a produção agrícola, e o descarte inadequado de suas embalagens podem contaminar o meio ambiente e ainda colocar em risco a saúde pública. Sendo assim, este trabalho tem por objetivo quantificar o volume de tipos de embalagens que foram processadas e encaminhadas para incineração e reciclagem pela Central de Recebimento de Embalagens Vazias de Agrotóxicos de Mossoró - RN nos anos de 2006 a 2014. Neste período deram entrada na central um total de 488.76 t de embalagens vazias de agrotóxicos e até o final de 2014, 450.53 t desse material foram processados e transportados para recicladoras ou incineradoras, totalizando aproximadamente $92 \%$ das embalagens recebidas pela Central. As embalagens de Polietileno de Alta Densidade e papelão foram as que representaram o maior percentual de processamento e retirada da Central 40,36 e $28,10 \%$, respectivamente. Em contrapartida, os menores valores percentuais de retirada foram para o aço e as tampas das embalagens 2,16 e 4,03\%, respectivamente. As embalagens contaminadas ou não laváveis representaram 11,44\% do valor total processado.

Palavras-chaves: logística reversa, meio ambiente, processamento de embalagens.

\begin{abstract}
Pesticides are substances used to control unwanted biological agents agricultural production, and improper disposal of its packaging can contaminate the environment, and endanger public health. Thus, this study aims to quantify the volume of packaging types that have been processed and sent for incineration and recycling by Empties Receiving Center of Pesticide Mossoro - RN in the years 2006 to 2014. In this period were received at central a total of 488.76 tons of empty pesticide containers and by the end of 2014, $450.53 \mathrm{t}$ of this material were processed and transported to recycling or incineration, totaling approximately $92 \%$ of packages received by the Central. Packaging of High Density Polyethylene and cardboard were those that represented the highest percentage of processing and withdrawal of Central 40.36 and $28.10 \%$, respectively. In contrast, smaller percentages were taken from the steel and to the lids of containers 2.16 and $4.03 \%$, respectively. Contaminated or not cleanable packaging accounted for $11.44 \%$ of the total amount processed.
\end{abstract}

Key words: reverse logistics, environment, packaging processing.

\footnotetext{
*Autor para correspondência

Recebido para publicação em 12/11/2015; aprovado em 16/12/2015

${ }^{1}$ Graduando(a) em Agronomia, Universidade Federal Rural do Semi-Árido (UFERSA), Mossoró - RN; E-mail: angela-saionara@hotmail.com, telianeln@hotmail.com

${ }^{2}$ Eng. Agrônomo, Prof. Dr. em Fitopatologia , Universidade Federal Rural do Semi-Árido (UFERSA), Mossoró - RN; E-mail: jrrui@ @otmail.com

${ }^{3}$ Doutorando(a) em Fitotecnia, Universidade Federal Rural do Semi-Árido (UFERSA), Mossoró - RN; E-mail: deia_mitsa@hotmail.com
} 


\section{INTRODUÇÃO}

Os agrotóxicos são produtos e agentes de processos físicos, químicos ou biológicos utilizados para o controle de organismos biológicos que por algum motivo possam afetar o desenvolvimento das culturas, possuindo ampla utilização durante todo o ciclo de cultivo. Destes, incluem-se: herbicidas, fungicidas, bactericidas, nematicidas, etc.

De acordo com o Ministério da Agricultura (2014), dentre os principais indicadores de "superávit" da balança comercial brasileira, o Agronegócio se destaca com aproximadamente $23 \%$ do Produto Interno Bruto (PIB), sendo a produção agrícola um dos principais itens de exportação.

Com o aumento da área cultivada, associado às mudanças nas técnicas de cultivo e introdução de ferramentas da biotecnologia, foi detectado um aumento considerável no número de pragas e doenças nas culturas de exportação do agronegócio brasileiro. Esse fato veio a refletir no volume de vendas de agrotóxicos no País.

Segundo dados do Instituto Brasileiro do Meio Ambiente e dos Recursos Naturais Renováveis (IBAMA, 2012) houve um aumento de $86,79 \%$ nas vendas anuais de agrotóxico no Brasil de 2006 a 2012, atingindo 477.729,44 toneladas (t) de ingredientes ativos (IA) comercializados, sendo estes utilizados ao longo de toda cadeia produtiva: produção, pós-colheita, armazenamento, fumigação de grãos, etc.

Em 2008, o Brasil assumiu o posto de maior consumidor de agrotóxicos em todo mundo, posição antes ocupada pelos Estados Unidos (ANVISA, 2009). Segundo dados do Sindicato Nacional da Indústria de Produtos para Defesa Vegetal (SINDIVEG, 2015) a indústria de defensivos agrícolas movimentou US\$ 11,454 bilhões em 2013, contra US\$ 9,710 bilhões em 2012.

Por conterem substâncias químicas que modificam o ambiente nas suas mais diferentes formas de vida, as embalagens de agrotóxicos são um dos tipos de resíduos que mais causam preocupação, e o principal motivo para darmos a destinação final correta para essas embalagens é diminuir o risco para a saúde das pessoas e contaminação do meio ambiente (CANTOS et al., 2008).

As embalagens quando não recebem a destinação correta são descartadas em rios, queimadas a céu aberto, abandonadas nas lavouras, enterradas, recicladas sem controle ou até reutilizadas para o acondicionamento de água e alimentos. Contaminam o meio ambiente e ainda coloca em risco a saúde pública.

Em 23 de Janeiro de 2001, entrou em vigor a Lei $\mathrm{n}^{\circ}$ 9.974/00 (BRASIL, 2000), que alterou a Lei $\mathrm{n}^{\mathbf{0}} 7.802 / 89$ (BRASIL, 1989), que obriga os usuários de agrotóxicos a devolverem as embalagens vazias e os resíduos de agrotóxicos aos comerciantes, e estes por sua vez, aos fabricantes.

O objetivo desta Lei é dar um tratamento adequado ao problema agrotóxico, atuando em todas as fases, desde a produção, comercialização, utilização e destinação final, regulando, estabelecendo responsabilidades e fiscalizando, buscando assim a solução e o controle do lixo tóxico, altamente prejudicial à natureza.
Após a instauração dessa lei, em 14 de dezembro de 2001, foi criado o Instituto Nacional de Processamento de Embalagens Vazias (inpEV), entidade sem fins lucrativos criada para gerir a destinação final dessas embalagens. Alguns anos depois, em 2004, foi implantada junto a essa entidade a Central de Embalagens Vazias de Agrotóxicos de Mossoró.

Conhecendo os impactos que essas embalagens descartadas inadequadamente podem causar ao meio ambiente, este trabalho possui como objetivo quantificar o volume de embalagens que foram processadas e encaminhadas para incineração e reciclagem pela Central de Recebimento de Embalagens Vazias de Agrotóxicos de Mossoró - RN entre os anos de 2006 e 2014.

\section{MATERIAL E MÉTODOS}

A coleta de dados e informações foi realizada com base em dados quantitativos de entrada (devolução de embalagens vazias do setor produtivo) e saída de embalagens (encaminhadas para reciclagem ou incineração) fornecido pela Central de Recebimento de Embalagens Vazias de Agrotóxicos do município de Mossoró no Rio Grande do Norte, localizada na zona rural do mesmo, Rod. RN 015 km 9, na estrada de Baraúna no sentido Mossoró - Baraúna, no período de 2006 a 2014. Sendo os dados apresentados estratificados por tipos de embalagens.

\section{RESULTADOS E DISCUSSÃO}

Os resultados obtidos nesta pesquisa indicam que no período de avaliação, compreendido entre os anos 2006 e 2014, deram entrada na Central de Descarte de Embalagens Vazias de Agrotóxicos um total de 488.76 t de embalagens vazias de produtos. No total, foram processados, e transportados para recicladoras ou incineradoras, $450.53 \mathrm{t}$, totalizando assim 92\% dos diferentes tipos de materiais de embalagens vazias de agrotóxicos devolvidas (Tabela 1).

Cabe destacar que das $450.53 \mathrm{t}$ de embalagens processadas e enviadas para as unidades recicladoras ou incineradoras, os maiores montantes foram de embalagens do tipo Polietileno de Alta Densidade (PEAD) (181.83t) e papelão (126.6t), vindo a representar um percentual de 40,36 e $28,10 \%$, respectivamente. Em contrapartida, os menores valores de descarte foram para o aço com $9.47 \mathrm{t}$ e as tampas das embalagens (18.15t), com um percentual de 2,16 e $4,03 \%$ dos materiais processados e enviados para recicladora ou incineradora (tabela 1).

As embalagens contaminadas ou não laváveis, por se tratarem de sacos plásticos ou de papelão laminado começaram a ser retirado da Central de Descarte somente a partir de 2012. Vindo a totalizar, ao final de três anos, 51.53t. Isso se deve a que, as cargas retiradas pela transportadora desse tipo de material somente a fazem quando a carga se encontra completa, sendo esta de aproximadamente 13t (tabela 1). 
Tabela 1. Valores de entrada e saída de embalagens vazias de agrotóxicos (t) por tipo de material, entre os anos de 2006 à 2014 pela Central de Descarte de Embalagens Vazias de Mossoró. Mossoró, UFERSA, 2015.

\begin{tabular}{cccccccccc}
\hline \multirow{2}{*}{ Ano } & \multirow{2}{*}{ Entrada } & \multicolumn{9}{c}{ Tipos de materiais processados } & \multirow{2}{*}{ Saída } & \multirow{2}{*}{ Restante } \\
\cline { 3 - 7 } & & Papelão & Coex & Tampa & Contaminada & Pead $^{\mathbf{2}}$ & Aço & & \\
\hline $\mathbf{2 0 0 6}$ & $35.00^{1}$ & 10.00 & 0.00 & 0.00 & 0.00 & 8.00 & 0.00 & 18.00 & 17.0 \\
$\mathbf{2 0 0 7}$ & 47.50 & 12.00 & 10.00 & 0.00 & 0.00 & 18.00 & 0.00 & 40.00 & 24.5 \\
$\mathbf{2 0 0 8}$ & 60.19 & 12.60 & 0.00 & 4.40 & 0.00 & 21.00 & 0.00 & 38.00 & 46.7 \\
$\mathbf{2 0 0 9}$ & 48.38 & 24.19 & 7.27 & 0,00 & 0.00 & 25.17 & 0.00 & 56.63 & 38.4 \\
$\mathbf{2 0 1 0}$ & 71.52 & 23.61 & 9.12 & 4.80 & 0.00 & 24.91 & 0.00 & 62.44 & 47.5 \\
$\mathbf{2 0 1 1}$ & 51.56 & 0.00 & 12.15 & 4.80 & 0.00 & 25.81 & 0.00 & 42.76 & 56.3 \\
$\mathbf{2 0 1 2}$ & 54.41 & 17.00 & 12.04 & 4.15 & 26.63 & 14.14 & 0.00 & 73.96 & 36.7 \\
$\mathbf{2 0 1 3}$ & 73.70 & 14.10 & 5.90 & 0.00 & 11.90 & 24.90 & 9.74 & 66.54 & 43.9 \\
$\mathbf{2 0 1 4}$ & 46.50 & 13.10 & 6.20 & 0.00 & 13.00 & 19.90 & 0.00 & 52.20 & 38.2 \\
\hline Total & 488.76 & 126.60 & 62.68 & 18.15 & 51.53 & 181.83 & 9.74 & 450.53 & \\
\hline$\%$ & & 28,10 & 13,91 & 4,03 & 11,44 & 40,36 & 2,16 & & \\
\hline
\end{tabular}

${ }^{1}$ Valores expressos em toneladas. ${ }^{2}$ Polietileno de alta densidade.

Em trabalho realizado por Gomes (2006) avaliando a Destinação final das embalagens vazias de agrotóxicos na cidade de Goiânia, também se constatou que as embalagens PEAD apresentaram o maior percentual no quantitativo devolvido e processado, representando $64 \%$ do volume total de embalagens prensadas, evidenciando que para a região do entorno de Goiânia a maioria dos agrotóxicos usados na região são de embalagens laváveis.

Observou-se uma permanência das embalagens contaminadas no interior da central de descarte no período de 2006 a 2011. Isso se deveu no primeiro momento a uma indefinição a respeito de seu processamento, e no segundo momento, devido a uma exigência feita pela Empresa transportadora responsável por este tipo de material, e que trabalha em parceria direta com o inpEV no sistema de logística reversa, o qual solicitava o licenciamento de transporte da Central de Embalagens de Mossoró. Dessa forma, por definição do Instituto de Desenvolvimento Sustentável e Meio Ambiente do Rio Grande do Norte IDEMA (Órgão responsável pela política ambiental do Estado do RN) foi determinado o seu licenciamento no ano de 2012, momento no qual a empresa transportadora começou a operar na retirada da carga contaminada.

Também se observa que em relação às embalagens de aço, somente a partir de 2013 foi liberada a primeira remessa de material para recicladora. Isso se deveu a que o volume recebido, mais precisamente de embalagens antigas de agrotóxicos e de sementes, e não completava uma carga completa, que nesse caso seria de aproximadamente $10 \mathrm{t}$.

Outro ponto em destaque a se considerar é parte do montante total das embalagens que são devolvidas na central de descarte, apenas uma parte é processada para envio a recicladora ou incineradora. Isso se deve a que a logística reversa realizada pela empresa transportadora de produtos agrotóxicos somente leva o material quando a carga se encontra completa na sua tonelagem. Dessa forma, sempre sobra parte desse material que fica já processado para o ano seguinte. Associado a isso, é importante frisar que as cargas devem ser do mesmo material, nunca poderá haver misturas, haja vista as recicladoras que recebem esse material lavável não trabalharem com materiais misturados. Sendo assim, materiais como tampas, aço, e contaminados sempre tardam mais em serem retirados da central de descarte. Além de que, as unidades recicladoras pagam esse material por quilograma, no caso de misturas esse valor tende a cair de preço.

\section{CONSIDERAÇÕES FINAIS}

De acordo com os resultados apresentados, concluise que as ações do governo, junto com instituições como inpEV, têm colaborado para colocar o Brasil na primeira posição em reutilização e destinação correta de embalagens vazias de agrotóxicos. O aumento da conscientização no manejo dessas embalagens e sua logística reversa são imprescindíveis para a redução do impacto ambiental, causado por tal atividade.

\section{REFERÊNCIAS BIBLIOGRÁFICAS}

AGÊNCIA NACIONAL DE VIGILÂNCIA SANITÁRIA ANVISA. Reavaliação dos agrotóxicos: 10 anos de proteção a população. http://www.anvisa.gov.br/divulga/noticias/2009/020409.ht m. Acesso em 10 Dez. 2015.

BRASIL. Lei 7.802, de 11 de julho de 1989. Diário Oficial da União, Brasília, DF, 12 jul.1989.

BRASIL. Lei 9.974, de 6 de junho de 2000. Coleção de Leis do Brasil - 2000, Página 3637 Vol. 6.

CANTOS, C.; MIRANDA, Z. A. I; LICCO, E. A. Contribuiçõos Para a Gestão das Embalagens Vazias de Agrotóxicos. Gestão Integrada em Saúde do Trabalho e Meio Ambiente, São Paulo, v.3, n.2, 36p. 2008.

GOMES, R, V. Destinação final das embalagens vazias de agrotóxicos na cidade de Goiânia. 
http://www.ucg.br/ucg/prope/cpgss/ArquivosUpload/36/fil e/Continua/DESTINA\%C3\%87\%C3\%830\%20FINAL $\% 2$ 0DAS\%20EMBALAGENS\%20VAZIAS\%20DE\%20AG ROT\%C3\%93XICOS\%20NA\%20CIDADE\%20DE\%20G OI\%C3\%82NIA.pdf. 18 Ago. 2015

IBAMA. Instituto brasileiro do meio ambiente e dos recursos naturais renováveis. Boletim de comercialização de agrotóxicos e afins - Histórico das vendas- 2000 a 2012. http://www.ibama.gov.br/phocadownload/Qualidade_Am biental/boletim\%20de\%20comercializacao_2000_2012.pd f. Acesso em 12 dez. 2015.

MDA. Ministério da Agricultura. Produto Interno Bruto da agropecuária deve ser de $\mathrm{R} \$ 1,1$ trilhão. http://www.agricultura.gov.br/comunicacao/noticias/2014/ 12/produto-interno-bruto-da-agropecuaria-deve-ser-de-rs1-trilhao.02 Set.2015.

SINDIVAG. Sindicato nacional da indústria de produtos para devesa vegetal. http://www.sindiveg.org.br/sindiveg.php. 30 Jul. 2015. 